\title{
Interferência da condição climática na integridade de espermatozoides ovinos submetidos à criopreservação
}

[Climate condition interference on ram spermatozoa integrity submitted to cryopreservation]

\author{
S.V. Silva ${ }^{1 *}$, A.T. Soares ${ }^{1,2}$, A.M. Batista ${ }^{1,3}$, F.C. Almeida ${ }^{1}$, M.M.P. Guerra ${ }^{1}$ \\ ${ }^{1}$ Laboratório de Andrologia - Departamento de Medicina Veterinária - UFRPE \\ Av. Dom Manoel de Medeiros, s/n. Dois Irmãos \\ 52171-900 - Recife, PE \\ ${ }^{2}$ Empresa Estadual de Pesquisa Agropecuária da Paraíba - EMEPA - João Pessoa, PB; \\ ${ }^{3}$ Curso de Doutorado da Rede Nordeste de Biotecnologia - RENORBIO
}

\begin{abstract}
RESUMO
Avaliou-se a integridade de espermatozoides ovinos colhidos e criopreservados em diferentes situações climáticas na região semiárida do estado da Paraíba. As colheitas de sêmen foram realizadas em duas épocas do ano, período seco e período chuvoso, utilizando cinco machos adultos da raça Santa Inês, com histórico favorável de fertilidade. Os ejaculados foram avaliados quanto à motilidade, vigor, concentração e morfologia espermática, após a formação do pool e diluição em Tris-gema, na concentração final de $240 \times 10^{6}$ espermatozoides/mL. Motilidade total e vigor espermático não diferiram entre as épocas seca e chuvosa. Valores de integridade do acrossoma e da membrana plasmática, e o potencial de membrana mitocondrial foram mais baixos $(\mathrm{P}<0,05)$ na época com menor índice pluviométrico. Conclui-se que a reprodução de ovinos criados na região do semiárido paraibano sofre ação da condição climática e sugerese que a criopreservação de espermatozoides ovinos seja realizada no período de maior índice pluviométrico na região.
\end{abstract}

Palavras-chave: ovino, acrossoma, membrana plasmática, potencial mitocondrial

\begin{abstract}
Ram spermatozoa integrity collected and cryopreserved in different climatic situations in the semiarid region of Paraíba state was evaluated. Semen samples were collected in two periods: a dry and a rainy season, using five mature Santa Inês males, with favorable historical fertility. Ejaculates were evaluated for motility, vigor, concentration and morphology, after a pool formation and dilution in Tris-yolk egg, at $240 \times 10^{6} / \mathrm{mL}$ final concentration. Motility and sperm vigor did not differ between dry and rainy seasons. Acrosome integrity, plasma membrane and mitochondrial membrane potential were lower $(P>0.05)$ at the time with less rainfall. We concluded that sheep reproduction raised in semi-arid Paraiba region suffers climatic condition influence and the lowest rainfall period is deleterious to the sperm cells integrity subjected to cryopreservation process. It is suggested that ram spermatozoa cryopreservation be done in period of greatest rainfall in this region.
\end{abstract}

Keywords: ram, acrosome, plasma membrane, mitochondrial potential

\section{INTRODUÇÃO}

Os pequenos ruminantes são animais sazonais e, embora não apresentem estação de monta restrita, a atividade sexual é mais intensa no outono, e reduzida no fim do inverno, e na primavera e verão. Leboeuf et al. (2008), ao trabalharem com pequenos ruminantes no continente europeu, demonstraram que, fora da estação de monta, foi observada redução significativa no comportamento sexual, no tamanho testicular, no índice da atividade

Recebido em 6 de maio de 2010

Aceito em 1 de julho de 2011

*Autor para correspondência (corresponding author)

E-mail: sildivane@yahoo.com.br 
espermatogênica e na qualidade/quantidade de produção espermática. Essas características estão relacionadas a animais criados em regiões de clima temperado, onde são classificados como poliéstrico estacional. Em países de clima tropical, como o Brasil, os pequenos ruminantes sofrem menor ação do fotoperíodo, porém outros fatores interferem diretamente na condição reprodutiva, como a qualidade da alimentação e o estresse térmico (Simplício, 2008).

Cavalcante et al. (2005), em estudo na região Sudeste do Brasil, relataram que caprinos leiteiros e de corte não sofrem ação do fotoperíodo, uma vez que não evidenciam interferência da estação climática na atividade mitocondrial da célula espermática. Afirmaram que é possível colher e utilizar sêmen caprino em diferentes períodos do ano. Outros estudos demonstraram existir correlação entre a qualidade espermática e a condição climática, sendo a qualidade dos ejaculados mais baixa em períodos com menor incidência de chuvas (Silva et al., 1991; Aleu, 1992).

De acordo com Coelho et al. (2008), temperaturas elevadas podem interferir negativamente na temperatura testicular e, consequentemente, na qualidade espermática de pequenos ruminantes. Dentre as características seminais mais afetadas pela temperatura destacam-se a redução da motilidade e o aumento da porcentagem de espermatozoides anormais. Consequentemente sugere-se perda na capacidade fertilizante do espermatozoide, que necessita apresentar as membranas íntegras para ser considerado potencialmente fértil (Soares e Guerra, 2009).

Este estudo teve como objetivo avaliar a integridade de espermatozoides criopreservados ovinos colhidos em diferentes situações climáticas na região semiárida do estado da Paraíba.

\section{MATERIAL E MÉTODOS}

A colheita e a congelação de sêmen foram realizadas no município de Tacima, microrregião agreste do estado da Paraíba, com clima tropical semiárido e $06^{\circ} 29^{\prime} 18^{\prime \prime}$ de latitude sul e $35^{\circ} 38^{\prime} 14$ " de longitude oeste, altitude de $168 \mathrm{~m}$ e precipitação média anual de $431,8 \mathrm{~mm}$ (Brasil, 2005). A colheita de sêmen foi realizada em duas situações climáticas: 1) em fevereiro de 2008 e 2009, correspondendo à ausência de chuvas e vegetação escassa, caracterizado por período seco (precipitação de $20,1 \mathrm{~mm}^{3}$ ); 2) em junho de 2008 e 2009, correspondendo à época de alto índice pluviométrico, caracterizada por período chuvoso (precipitação de $159,4 \mathrm{~mm}^{3}$ ).

Foram utilizados cinco machos adultos da raça Santa Inês, com histórico favorável de fertilidade. Os animais foram mantidos em sistema de criação intensivo, com fornecimento de capim picado (Pennisetum purpureum) no cocho, concentrado, mineralização e água à vontade durante todo o período do experimento. Para colheita de sêmen, utilizou-se o método da vagina artificial, com uma fêmea em estro como manequim. As colheitas foram realizadas em dias alternados, totalizando 12 repetições por período e por ano.

Inicialmente, as amostras de sêmen foram avaliadas quanto ao turbilhonamento, motilidade e vigor em microscópio de contraste de fase (Olympus optical Co., Ltda., Tóquio, Japão), com a colocação de $10 \mu \mathrm{L}$ em lâmina previamente aquecida $\left(37^{\circ} \mathrm{C}\right)$ para turbilhonamento e deposição de lamínula 20x20 sobre a gota para avaliação da motilidade e do vigor. A concentração espermática foi obtida em câmara de Neubauer, na diluição de 1:200, em formol salino. Para análise da morfologia espermática, utilizou-se o método de câmara úmida, segundo o CBRA (Manual..., 1998).

O sêmen foi avaliado separadamente e quando aprovado - turbilhonamento $\geq 3$; motilidade $\geq 70 \%$; vigor $\geq 3$; concentração espermática $\geq 1,0 \times 10^{9} / \mathrm{mL}$ e patologias espermáticas $\leq 20 \%$ foi submetido à formação do pool e diluição em Tris-gema $(3,605 \mathrm{~g}$ de Tris; $2,024 \mathrm{~g}$ de ácido cítrico; $1,488 \mathrm{~g}$ de frutose; $100 \mathrm{~mL}$ de água bidestilada; $20 \%$ de gema de ovo, $5 \%$ de glicerol e pH 7,2), na concentração final de $240 \times 10^{6}$ espermatozoides $/ \mathrm{mL}$. Foi acondicionado em palhetas $(0,25 \mathrm{~mL})$ e submetido à congelação por sistema automatizado $\left(\mathrm{TK}-3000^{\circledR}\right.$, TK Tecnologia em congelação Ltda., Uberaba, MG). Após a congelação, as amostras de sêmen, armazenadas em nitrogênio líquido $\left(-196{ }^{\circ} \mathrm{C}\right)$, só foram avaliadas após um período mínimo de armazenamento de 30 dias. 
As amostras de sêmen criopreservadas foram descongeladas a $37^{\circ} \mathrm{C}$ por 30 segundos e submetidas à análise da motilidade total e vigor, da integridade da membrana plasmática e do acrossoma, e da atividade mitocondrial. As avaliações de motilidade total e vigor foram realizadas com a mesma metodologia para o sêmen recém-colhido.

Para avaliação da integridade da membrana plasmática, utilizou-se o método de coloração dupla com diacetato de carboxifluoresceína (DCF; Sigma-Aldrich ${ }^{\circledR}$, St Louis, MO, USA) e iodeto de propídeo (IP; Sigma-Aldrich ${ }^{\circledR}$, St Louis, MO, USA), modificado por Coleto et al. (2002). Alíquotas de $50 \mu \mathrm{L}$ de sêmen foram diluídas em $150 \mu \mathrm{L}$ de Tris $(3,605 \mathrm{~g}$ de Tris; $2,024 \mathrm{~g}$ de ácido cítrico; $1,488 \mathrm{~g}$ de frutose, $100 \mathrm{~mL}$ de água bidestilada; pH 6,8), contendo $5 \mu \mathrm{L}$ de DCF $(0,46 \mathrm{mg} / \mathrm{mL}$ em DMSO) e $20 \mu \mathrm{L}$ de IP $(0,5 \mathrm{mg} / \mathrm{mL}$ em PBS $)$, incubadas por 10 minutos a $37^{\circ} \mathrm{C}$ e fixadas com PBS contendo $0,5 \%$ de glutaraldeído. Um total de 200 espermatozoides foi avaliado em microscópio de epifluorescência (Carl Zeiss, Göttingen, Alemanha), com aumento de 400x, usando filtro de emissão DBP 580-630nm e excitação DBP 485-520nm, e classificado com membrana intacta, quando se apresentava corado em verde, e com membrana danificada, quando corado em vermelho.

Para determinar a integridade do acrossoma, os espermatozoides foram corados com isotiocíanato de fluoresceína conjugado a Peanut agglutinin (FITC-PNA; Sigma-Aldrich ${ }^{\circledR}, \quad \mathrm{St}$ Louis, MO, USA), de acordo com a técnica descrita por Roth et al. (1998). Alíquotas de $5 \mu \mathrm{L}$ de sêmen foram preparadas para esfregaço e secadas ao ar. Uma alíquota de $100 \mu \mathrm{L}$ da solução estoque de FITC-PNA (1mg/mL) foi descongelada e adicionada a $900 \mu \mathrm{L}$ de PBS para obter a concentração final de $100 \mu \mathrm{g} / \mathrm{mL}$. Alíquotas (10-20 $\mu \mathrm{L})$ desta solução foram colocadas sobre lâminas, as quais foram incubadas por 15 minutos em câmara úmida a $4^{\circ} \mathrm{C}$, na ausência de luz. Após incubação, as lâminas foram enxaguadas duas vezes em PBS refrigerado $\left(4^{\circ} \mathrm{C}\right)$ e colocadas para secagem na ausência de luz. Imediatamente antes da avaliação, $5 \mu \mathrm{L}$ de meio de montagem $(4,5 \mathrm{~mL}$ de glicerol, $0,5 \mathrm{~mL}$ de PBS e $5 \mathrm{mg}$ de pphenylenediamine) foram colocados sobre a lâmina e coberto com lamínula.
Foram avaliados 200 espermatozoides por lâmina, com aumento de 1000x sob óleo de imersão em microscopia de epifluorescência, usando filtro de emissão LP 515nm e BP 450$490 \mathrm{~nm}$ para excitação. Os gametas foram classificados como portadores de acrossomas intactos quando apresentavam a região acrossomal corada com fluorescência verde, ou acrossomas reagidos, quando apresentavam faixa verde fluorescente na região equatorial da cabeça espermática ou não apresentavam fluorescência verde em toda a cabeça da célula.

A atividade mitocondrial dos espermatozoides foi determinada pela utilização do fluorocromo catiônico lipofílico JC-1 (Guthrie e Welch, 2006). Alíquotas de $50 \mu \mathrm{L}$ de sêmen foram diluídas em $150 \mu \mathrm{L}$ de Tris contendo $5 \mu \mathrm{L}$ de JC-1 $(0,15 \mathrm{mM}$ em DMSO), incubadas por 10 minutos a $38^{\circ} \mathrm{C}$ e fixadas com PBS contendo $0,5 \%$ de glutaraldeído. Duzentos espermatozoides foram avaliados em microscópio de epifluorescência, com aumento de 1000x sob óleo de imersão, usando filtro de emissão LP $515 \mathrm{~nm}$ e BP 450490nm para excitação. As células que apresentavam a peça intermediária corada em laranja foram classificadas com alto potencial de membrana mitocondrial, enquanto as coradas em verde foram classificadas com baixo potencial de membrana

Os dados foram expressos na forma de média e desvio-padrão. Para motilidade total, vigor, integridade da membrana plasmática, acrossoma e potencial mitocondrial, foram utilizados a análise de variância e o teste de Bartlett para constatar a homogeneidade entre as variâncias; e o teste de comparação múltipla de TukeyKramer, com significância de $\mathrm{P}<0,05$.

\section{RESULTADOS E DISCUSSÃO}

Os resultados das análises das características espermáticas pós-descongelação encontram-se na Tab. 1. Motilidade e vigor espermáticos não diferiram $(\mathrm{P}>0,05)$ em razão das condições climáticas e foram considerados aprovados pelos critérios mínimos $(30 \%$ de motilidade e 3 de vigor) estabelecidos pelo CBRA (Manual..., 1998) para sêmen pós-descongelação.

A não diferença na motilidade entre o sêmen colhido nas épocas seca e chuvosa corroboram com resultados anteriores de haver pouca ou 
nenhuma influência da estação climática sobre a condição reprodutiva nessa região tropical (Simplício, 2008). Segundo Cavalcante et al. (2005), na rotina de análise de sêmen para a predição da fertilidade, concentração espermática, motilidade subjetiva e percentual de patologias espermáticas, tanto para o sêmen fresco como para o pós-criopreservado, são amplamente utilizadas em campo. Entretanto, a avaliação da motilidade é limitada e não corresponde unicamente à habilidade de fertilização dos gametas masculinos, uma vez que espermatozoides podem apresentar movimento, mas não estar íntegros quanto às membranas (Maziero et al., 2009).

Tabela 1. Características morfológicas (média \pm desvio-padrão) de espermatozoides de ovinos da raça Santa Inês, congelados nos períodos chuvoso e seco, no semiárido paraibano

\begin{tabular}{lcc}
\hline & Período chuvoso & Período seco \\
\hline Motilidade total (\%) & $57,82 \pm 4,98 \mathrm{a}$ & $51,31 \pm 6,45 \mathrm{a}$ \\
Vigor (escala 0-5) & $2,50 \pm 0,55 \mathrm{a}$ & $2,60 \pm 0,55 \mathrm{a}$ \\
iAc (\%) & $40,33 \pm 6,25 \mathrm{a}$ & $11,75 \pm 5,04 \mathrm{~b}$ \\
iMP (\%) & $41,25 \pm 2,16 \mathrm{a}$ & $25,17 \pm 6,84 \mathrm{~b}$ \\
PMM (\%) & $76,83 \pm 13,84 \mathrm{a}$ & $39,50 \pm 9,79 \mathrm{~b}$ \\
\hline
\end{tabular}

iMP: integridade da membrana plasmática; iAc: integridade do acrossoma; PMM: potencial da membrana mitocondrial. Letras distintas na mesma linha indicam diferença entre valores (teste de Tukey; $\mathrm{P}<0,05$ ).

Segundo Kumar (2000), a motilidade progressiva é importante para a viabilidade espermática após o processo de criopreservação, sendo esta a característica mais importante para a fertilização. Siqueira et al. (2007) avaliaram a correlação da motilidade progressiva com a taxa de prenhez em fêmeas bovinas e constataram que não houve interferência da motilidade sobre a taxa de prenhez ou correlação positiva entre essas duas características. Xu et al. (1998) avaliaram a importância da motilidade, concentração e morfologia na inseminação de fêmeas suínas e observaram que a alta motilidade não foi significativa para determinar o aumento na taxa de prenhez, e que a baixa concentração espermática diminuiu o tamanho da leitegada, e a qualidade morfológica dos espermatozoides conferiu maior fertilidade.

Dessa forma, técnicas mais precisas foram utilizadas neste experimento para estimar com maior repetibilidade e confiabilidade a capacidade fertilizante dos espermatozoides ovinos pós-descongelação. A integridade do acrossoma (iAc) foi significativamente mais baixa $(\mathrm{P}<0,05)$ na estação com menor índice pluviométrico, assim como a integridade da membrana plasmática (iMP) e o potencial da membrana mitocondrial (PMM). Sabe-se que células espermáticas com as características observadas no período de seca resultam em índices de fertilidade mais baixos, uma vez que a presença de membranas íntegras é um prérequisito para os eventos relacionados ao processo de fertilização, como a capacitação espermática, a penetração no revestimento do ovócito, a ligação à zona pelúcida e a fusão com o oolema (Soares e Guerra, 2009).

No momento da criopreservação, alterações na membrana são ocasionadas pela necessidade de adaptação das células espermáticas às mudanças da temperatura (Farstad, 2009). Neste estudo, houve interferência da condição climática sobre as características espermáticas pósdescongelação. De acordo com Santos et al. (2006), durante o período seco há menor concentração de testosterona, hormônio que atua diretamente nos componentes do plasma seminal, como a frutose e o ácido cítrico. Dessa forma, quando há menor concentração hormonal, principalmente associada à menor condição nutricional, diminuem os substratos que oferecem proteção aos espermatozoides durante a ejaculação e, consequentemente, há menor resistência às mudanças de temperatura, ocorridas na criopreservação.

Quanto ao potencial da membrana mitocondrial, no período seco há redução nos valores de atividade das mitocôndrias. Se os ejaculados colhidos durante o período seco apresentam a maior parte de suas células com baixo potencial mitocondrial, provavelmente estas células não conseguem sobreviver por muito tempo no ambiente uterino, uma vez que os espermatozoides precisam de suporte energético para o movimento de cauda e posteriormente 
alcançar o oócito (Gadella, 2008). Estes resultados diferem dos encontrados por Cavalcante et al. (2005), que, ao trabalharem com caprinos, evidenciaram atividade mitocondrial estável independentemente da estação climática. Como esses autores utilizaram outra técnica para avaliação da função mitocondrial, outra espécie e região climática diferenciada, os resultados não podem ser equiparados.

Martins et al. (2003), ao trabalharem com ovinos, destacaram aumento do percentual de anormalidades espermáticas, principalmente defeitos de cabeça e peça intermediária, durante a época de seca, evidenciando, nesse caso, reatividade ao fotoperíodo, concomitante à deficiência nutricional. Esses resultados podem ser comparados com os do presente estudo, pois as patologias espermáticas podem ser provenientes da instabilidade da membrana plasmática, que, ao se apresentar lesionada, favorece a ocorrência de alterações estruturais localizadas na cauda, em razão da deficiência na função da membrana. Estando a membrana plasmática instável, propensa a lesões, outras estruturas podem sofrer danos, como as membranas do acrossoma e a mitocondrial, diminuindo, dessa forma, a resistência das células espermáticas aos processos de criopreservação, como a refrigeração e a congelação (Soares e Guerra, 2009).

Outro ponto que deve ser ressaltado é o conforto térmico. Os animais, mesmo em condições de boa alimentação, podem não desenvolver seu potencial reprodutivo em decorrência do desconforto térmico ocasionado por períodos de menor precipitação pluviométrica (Brasil et al., 2000). Na condição de estresse térmico, há aumento da respiração para facilitar a ventilação pulmonar, troca intensa de calor para manutenção das atividades vitais, menor ingestão de alimentos sólidos e maior consumo de compostos líquidos (Aguiar et al., 2007). Nas condições deste experimento, os reprodutores, mantidos em sistema intensivo, receberam alimentação de boa qualidade no período de seca, mas podem ter sofrido ação do estresse térmico, interferindo diretamente na espermatogênese, que não seria, para o animal, atividade vital no sistema biológico (Kolb, 1987). Assim, os espermatozoides produzidos no período de menor índice pluviométrico apresentaram menor resistência ao processo de criopreservação, sendo identificadas mais lesões nas membranas responsáveis pela capacidade fertilizante da célula espermática.

\section{CONCLUSÕES}

Conclui-se que ovinos criados na região do semiárido paraibano e em boas condições de alimentação sofrem ação da condição climática, sendo o período de menor índice pluviométrico deletério à integridade da célula espermática submetida ao processo de criopreservação. Sugere-se que a criopreservação de espermatozoides ovinos seja realizada no período de maior índice pluviométrico nesta região.

\section{REFERÊNCIAS BIBLIOGRÁFICAS}

AGUIAR, F.C.; LEITE, E.R.; ELOY, A.M.X. Impactos do estresse sobre a produção animal. Sobral: Embrapa Caprinos, 2007. 26p.

ALEU, J.R. Variaciones estacionales de la congelabilidad del semen caprino. In: JORNADAS INTERNACIONALES DE REPRODUCCIÓN ANIMAL Y INSEMINACIÓN ARTIFICIAL, 6., 1992. Salamanca. Anais... Libro de ponencias y mesas redondas, 1992. p.235-246.

BRASIL. Projeto cadastro de fontes de abastecimento por água subterrânea do estado da Paraíba Diagnóstico do Município de Campo de Santana, 2005. 20p.

BRASIL, L.H.A.; WECHESLER, F.S.; BACCARI Jr., F. et al. Efeitos do estresse térmico sobre a produção, composição química do leite e respostas termorreguladoras de cabras da raça Alpina. Rev. Bras. Zootec., v.29, p.1632-1641, 2000.

CAVALCANTE, T.V.; ESPER, C.R.; FERREIRA, J.L. et al. Avaliação da atividade mitocondrial em espermatozoides pós-colheita e pós-descongelação de caprinos das raças Boer e Alpina no outono e primavera. Arch. Vet. Sci., v.10, p.89-93, 2005.

COELHO, L.A.; SASA, A.; BICUDO, S.D. et al. Concentrações plasmáticas de testosterona, triiodotironina (T3) e tiroxina (T4) em bodes submetidos ao estresse calórico. Arq. Bras. Med. Vet. Zootec., v.60, p.1338-1345, 2008.

COLETO, Z.F.; GUERRA, M.M.P.; BATISTA, A.M. Avaliação do sêmen congelado de caprinos com drogas fluorescentes. Rev. Bras. Med. Vet., v.24, p.101-104, 2002.

FARSTAD, W. Cryopreservation of canine semen New Challenges. Reprod. Domest. Anim., v.44, p.336341, 2009. 
GADELLA, B.M. Sperm membrane physiology and relevance for fertilization. Anim. Reprod. Sci., v.107, p.229-236, 2008.

GUTHRIE, H.D.; WELCH G.R. Determination of intracellular reactive oxygen species and high mitochondrial membrane potential in Percoll-treated viable boar sperm using fluorescence-activated flow cytometry. J. Anim. Sci., v.84, p.2089-2100, 2006.

KOLB, E.A. Fisiologia da reprodução. In: Fisiologia Veterinária. 4.ed. Rio de Janeiro: Guanabara Koogan, 1987. p.374-412.

KUMAR, S. Cellular damages during cryopreservation and assessment of in vitro fertilizing capacity of spermatozoa. Indian Vet. Med. J., v.24, p.1-6, 2000.

LEBOEUF, B.; DELGADILLO, J.A.; MANFREDI, E. et al. Management of goat reproduction and insemination for genetic improvement in France. Reprod. Domest. Anim., v.43, suppl.2, p.379-385, 2008.

MANUAL para exame andrológico e avaliação do sêmen animal. Belo Horizonte: Colégio Brasileiro de Reprodução Animal. 2.ed., 1998. 49p.

MARTINS, R.D.; McMANUS, C.; CARVALHÊDO, A.S. et al. Avaliação da sazonalidade reprodutiva de carneiros Santa Inês criados no Distrito Federal. Rev. Bras. Zootec., v.32, p.1594-1603, 2003.

MAZIERO, R.R.D.; CRESPILHO, A.M.; FREITASDELL'AQUA, C.P. et al. Análise de sêmen bovino e sua relação com a fertilidade. Rev. Bras. Reprod. Anim., n.6, supl., p.5-10, 2009.
ROTH, T.L.; WEISS, R.B.; BUFF, J.L. et al. Heterologous in vitro fertilization and sperm capacitation in an endangered African antelope, the Scimitar-Horned Oryx (Oryx dammah). Biol. Reprod., v.58, p.475-482, 1998.

SANTOS, A.D.F.; TORRES, C.A.A.; FONSECA, J.F.; et al. Parâmetros reprodutivos de bodes submetidos ao manejo de fotoperíodo artificial. $R$. Bras. Zootec., v.35, p.1926-1933, 2006.

SIMPLÍCIO, A.A. Estratégias de manejo reprodutivo como ferramenta para prolongar o período de oferta de carnes caprina e ovina no Brasil. Tecnol. Cienc. Agrop., v.2, p.29-39, 2008.

SILVA, A.E.D.F.; DODE, M.A.; PORTO, J.A. et al. Estacionalidade na atividade sexual de machos bovinos Nelore e mestiços Fleckvieh x Nelore e Chianina x Nelore. Pesq. Agrop. Bras., v.26, p.17511760, 1991.

SIQUEIRA, J.B.; GUIMARÃES, J.D.; COSTA, E.P. et al. Relação da taxa de gestação com sêmen bovino congelado e testes de avaliação espermática in vitro. Rev. Bras. Zootec., v.36, p.387-395, 2007.

SOARES, A.T.; GUERRA, M.M.P. Efeitos da criopreservação sobre a viabilidade espermática. Tecnol. Cienc. Agrop., v.3, p.53-63, 2009.

XU, X.; POMMIER, S.; ARBOV, T. et al. In vitro maturation and fertilization techniques for assessment of semen quality and boar fertility. J. Anim. Sci., v.76, p.3079-3089, 1998. 